Available online on 15.12.2020 at http://jddtonline.info
Open Access to Pharmaceutical and Medical Research
unrestricted non-commercial use (CC By-NC), provided the original work is properly cited

Open Access

Research Paper

\title{
Management of Non-Infectious Aneurisms of the Sub-Kydney Abdominal Aorta at the CHU/JRA
}

\author{
HF Randrianandrianina ${ }^{1}$, ZL Randimbinirina ${ }^{1 *}$, T Rajaobelison ${ }^{1}$, TG Rajaoharimalala ${ }^{1}$, RNAL \\ Rakotorahalahy ${ }^{1}$, AJC Rakotoarisoa ${ }^{2}$, AML Ravalisoa ${ }^{2}$ \\ (1) Department of Surgery, Faculty of Medicine of Antananarivo, Antananarivo, Madagascar \\ (2) Department of Surgery, Faculty of Medicine of Antananarivo, University of Antananarivo, Antananarivo, Madagascar
}

\begin{abstract}
Introduction: The aim of this study was to describe the principle of the management for non-infectious aneurysm of the sub-kidney abdominal aorta at the university teaching hospital/JRA Ampefiloha.

Materials and methods: It was a retrospective, descriptive study conducted at cardiovascular surgery department of the university teaching hospital/JRA Ampefiloha, for a period of 14 years old (January 2005 to December 2019), including all patients who had an non-infectious aneurysm of the subrenal abdominal aorta at the CHU/JRA Ampefiloha operated on or not.

Results: Sixty-one cases were included, with an mean age of 61.71 years old (from 16 to 82 years old), a male predominance (sex ratio-1.34), high blood pressure, dyslipidemia, active smoking and physical inactivity were the predominant risk factors. The circumstances of discovery were often abdominal pain (52.45\%) and a flapping abdominal mass (47.54\%). Aortic doppler ultrasound and/or CT angiography allowed the diagnosis and describe the type of aneurysm. Most of them was fusiform in 49 cases (80.32\%) and sacciform in 12 cases (19.67\%), the majority of which had a diameter of between 50 and $60 \mathrm{~mm}(36.06 \%)$. Thirty-nine patients were operated on (63.93\%). Conventional surgery with the flattening of the aneurysm followed by a replacement with a prosthetic graft was our reference technique. Postoperative development was favorable in $82.05 \%$ of cases. The mortality rate was $6.56 \%$.
\end{abstract}

Conclusion: The hospital frequency of an abdominal aortic aneurysm was 1.53\% at the university teaching hospital/JRA Ampefiloha. Conventional surgery was our reference technique, saving the lives of our patients.

Keywords: Aneurysm, subrenal abdominal aorta, surgery, prosthesis.

Article Info: Received 07 Oct 2020; $\quad$ Review Completed 19 Nov 2020; $\quad$ Accepted 29 Nov 2020; Available online 15 Dec 2020

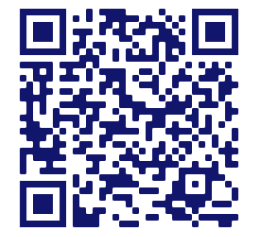

Cite this article as:

Randrianandrianina HF, Randimbinirina ZL, Rajaobelison T, Rajaoharimalala TG, Rakotorahalahy RNAL, Rakotoarisoa AJC, Ravalisoa AML, Management of Non-Infectious Aneurisms of the Sub-Kydney Abdominal Aorta at the CHU/JRA, Journal of Drug Delivery and Therapeutics. 2020; 10(6-s):11-15 http://dx.doi.org/10.22270/jddt.v10i6-s.4604

Dr Randimbinirina Zakarimanana Lucas, Department of Surgery, Faculty of Medicine Antananarivo, Antananarivo, 101, Madagascar

\section{INTRODUCTION}

Aneurysm is defined as a permanent, segmental dilation, with loss of parallelism of the edges ${ }^{1}$ or dilation greater than $50 \%$ of the normal diameter of the aortic proximal segment. Aortic aneurysm is subrenal if it is more than $1 \mathrm{~cm}$ downstream of the origin of the kidney arterie 2 . Abdominal aortic aneurysm is the most common site of a true arterial aneurysm, mainly affecting the subrenal segment of aorta. The overall prevalence of abdominal aortic aneurysms was $4.8 \%$ according to a $2013 \mathrm{Li}$ meta-analysis ${ }^{3}$. It is a serious condition endangering the life-threatening condition in the event of a rupture, with a pre-hospital mortality rate of $9 \% 4$. In Madagascar, data on the pathologies of the aneurysm of the sub-kidney abdominal aorta are still scarce. No protocol has been established for his surgical management.

The aim of this study was to describe the principle of the management for non-infectious aneurysm of the subrenal abdominal aorta at the university teaching hospital/JRA Ampefiloha.

\section{Methodology}

It was a retrospective, descriptive study conducted in the cardiovascular surgery department of the university teaching hospital/JRA Ampefiloha, for a period of 14 years old from January 2005 to December 2019. We included in this study all patients who presented a pure subrenal abdominal aortic aneurysm confirmed to doppler ultrasound 
and/or angioscanner of the non-infectious abdominal aorta. Other locations of aneurysm, such as suprarenal abdominal aortic aneurysm, isolated iliac or thoracic aneurysms, infectious aneurysm and incompletes folders have been excluded in this study. Socio-demographic data, discovery circumstances, imaging examinations results (morphology, location and antero-posterior diameter) and therapeutic management were analyzed. The data collected was analyzed with The Epi-info 7.1.3.3 software.

\section{RESULTS}

Sixty-one cases were collected among the 3974 admissions during this study period, giving a hospital frequency of $1.53 \%$. A male predominance was observed with 35 men and 26 women giving a sex ratio of 1.34 . The mean age was 61.71 years old with extremities of 16 years and 82 years old [Table I].

Table I: Socio-demographic data

\begin{tabular}{lcc}
\hline Socio-demographic data & No of patients / Results & Percent (\%) \\
\hline Total number of cases & $\mathbf{6 1}$ & $\mathbf{1 0 0}$ \\
Gender & 35 & 57,38 \\
- Male & 26 & 42,62 \\
- Female & 1,34 & \\
- Sex ratio & & \\
Age (years) & 61,71 years & \\
- Mean & 16 years & \\
- Minimum & 82 years & \\
Maximum & 3 & 4,92 \\
$\cdot[0-39]$ & 17 & 27,87 \\
$\cdot[40-49]$ & 22 & 36,07 \\
[50 - 59] & 11 & 18,03 \\
[60 - 69] & 8 & 13,11 \\
[70 and plus] & & \\
\hline
\end{tabular}

The most common risk factors were high blood pressure (81.97\%), age over 50 (70.49\%), smoking (63.93\%), dyslipidemia (57.38\%) male gender (57.38\%) [Table II].

Table II: Cardiovascular risk factors

\begin{tabular}{lcc}
\hline Cardiovascular risks factors & No of patients (Total=61) & Percent (\%) \\
\hline - Male gender & 35 & 57,38 \\
Age $>50$ years & 43 & 70,49 \\
- High blood pressure & 50 & 81,97 \\
- Diabetes mellitus & 8 & 13,11 \\
Smoking & 39 & 63,93 \\
Dyslipidemia & 35 & 57,38 \\
Sedentary & 28 & 45,90 \\
Obesity & 21 & 34,42 \\
\hline
\end{tabular}

The circumstances of discovery were dominated by a flapping abdominal mass (47.54\%) (Figure 1) and abdominal pain (52.46\%).

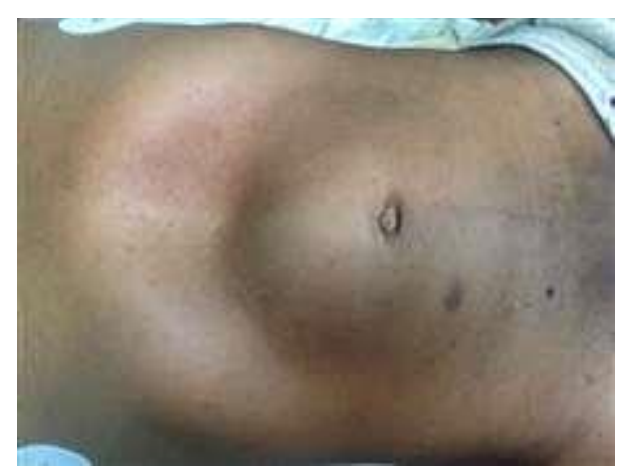

Figure 1: Abdominal mass (face) 
Aortic doppler ultrasound (97\%) and CT angiography of the aorta and limbs arteries (74\%) were the most requested follow-up examinations for diagnosis. Subrenal abdominal aortic aneurysms were fusiform in 49 cases (80\%) 11 cases (20\%), Most of them were had a diameter of between 50 and
$60 \mathrm{~mm}(36 \%)$. The average diameter of the aneurysm was $57.8 \mathrm{~cm}$. These aneurysms are isolated aortic location in 23 cases (38\%), aorto-bi-iliac in 35 cases (57\%) and aortobifemoral in 3 cases (5\%) [Table III].

Table III: Diagnosis

\begin{tabular}{|c|c|c|}
\hline Diagnosis & No of patients (Total=61) & Percent (\%) \\
\hline \multicolumn{3}{|l|}{ Circumstances of discovery } \\
\hline Flapping abdominal mass & 29 & 47,54 \\
\hline Abdominal pain & 32 & 52,46 \\
\hline Intermittent Claudication & 11 & 18,03 \\
\hline Rupture sign & 2 & 03,28 \\
\hline Compression sign & 10 & 16,39 \\
\hline \multicolumn{3}{|l|}{ Imagery requested } \\
\hline Chest X-ray & 42 & 68,85 \\
\hline Abdomen X-ray & 8 & 13,11 \\
\hline Abdominal ultrasound & 18 & 29,51 \\
\hline Aortic doppler ultrasound & 59 & 96,72 \\
\hline Aortic CT angiography & 45 & 73,77 \\
\hline \multicolumn{3}{|l|}{ Morphology of aneurysm } \\
\hline Fusiform aneurysm & 49 & 80,33 \\
\hline Sacciform aneurysm & 12 & 19,67 \\
\hline \multicolumn{3}{|l|}{ Location of the aneurysm } \\
\hline Isolated aortic aneurysm & 23 & 37,70 \\
\hline Aorto-bi-iliac aneurysm & 35 & 57,38 \\
\hline Aorto-bifémoral aneurysm & 3 & 4,92 \\
\hline \multicolumn{3}{|l|}{ Diameter of aneurysm } \\
\hline Less than $40 \mathrm{~mm}$ & 2 & 3,28 \\
\hline 40 to $50 \mathrm{~mm}$ & 17 & 27,87 \\
\hline 50 to $60 \mathrm{~mm}$ & 22 & 36,07 \\
\hline 60 to $70 \mathrm{~mm}$ & 11 & 18,03 \\
\hline 70 to $80 \mathrm{~mm}$ & 8 & 13,11 \\
\hline More than $80 \mathrm{~mm}$ & 1 & 1,64 \\
\hline
\end{tabular}

Management was surgical in 39 patients (64\%) 11 patients (18\%). Eight patients had discharged (13\%). The prostheses used were aorto-aortic (28\%), aorto-bi-iliac (67\%) (Figure 3.4), aorto-bifemoral (5\%). Protheses type are dominated by dacron (82\%) and PTFE (18\%).

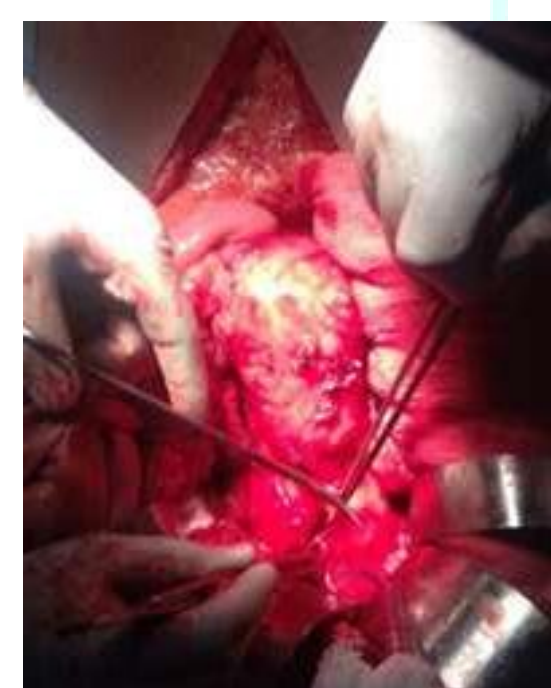

Figure 2: Subrenal abdominal aortic aneurysm (CHU/JRA)

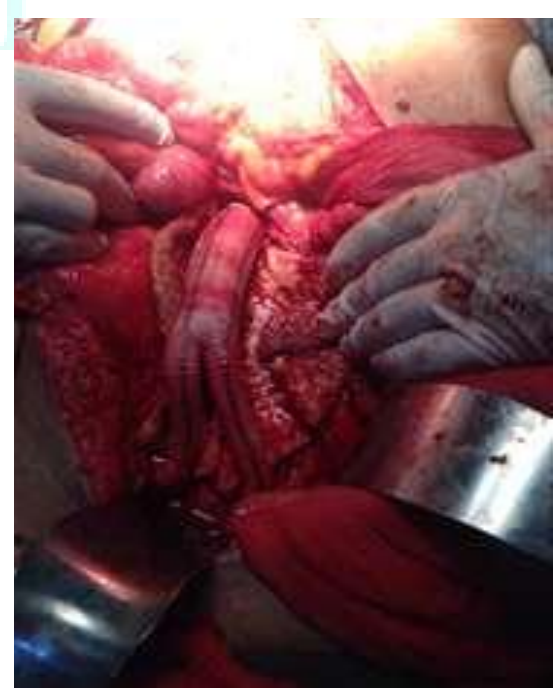

Figure 3: Aorto bi-iliac prosthetic replacement (CHU/JRA) 
The histological studies of the biopsic parts were able to find $95 \%$ of atheromatous origin and 5\% inflammatory.

Postoperative treatment includes generally, anticoagulants, antibiotic prophylaxis and painkillers (depending on the intensity of the pain). Two patients had died in preoperative conditions awaiting surgical treatment (3.28\%). Postoperative development was generally favorable $(82.05 \%)$. Two patients had died in the first thirty days in postoperative giving a post-operative mortality rate of $5 \%$ [Table III].

\section{DISCUSSION}

Abdominal aortic aneurysm is an elderly pathology. Its incidence is increasing due to the frequency of cardiovascular risk factors. Hospital prevalence was $1.53 \%$ in our series compared to other Western studies as in England with $1.7 \%{ }^{5}$ and in the United States with $2.5 \%{ }^{6}$. Moreover, an Algerian study by Ouarab showed a hospital frequency of $2.2 \%$ in Algeria 7.

The mean age of discovery of non-infectious aneurysms of the subrenal abdominal aorta varies according to the study. She was 61.71 years old in our study, 64 years old in the Senegalese study of Diengi 8 and 70.9 years old in the Gardet study [9. Male predominance in our series (Sex ratio 1.34) was observed in several study series, including Solofomalala (sex ratio-2.7), Stéphane (sex ratio-8) 10, Ting (sex ratio-5.6) 11 and Khan (sex ratio-6.5) 12. According to De Carvalho, there is a correlation between gender and the occurrence of abdominal aortic aneurysm 13. Indeed, there is a high statistically significant prevalence among the male gender (p-0.001) ${ }^{13}$.

Atherosclerosis is the main etiology of abdominal aortic aneurysm, apart from rare etiologies. The main risk factors are age over 65 years old, male gender, smoking, family history of abdominal aortic aneurysm, history of coronary heart disease, high blood pressure, peripheral arterial disease and anterior myocardial infarction 14. The prevalence of high blood pressure, smoking and diabetes in modifiable risk factors is similar to the study of Becker 15 and Ouarab ${ }^{7}$ in view of the prevalence of these risk factors (Table V). Some cardiovascular risk factors are blamed for abdominal aortic aneurysm rupture including a history of heart or kidney transplantation, female gender, high average blood pressure, wide initial diameter of abdominal aortic aneurysm, and smoking 16 .

The circumstances of discovery range from abdominal mass palpation to painful abdominal syndrome, or even cardiovascular collapse associated with aneurysmal rupture. For symptomatic forms, abdominal pain is the main telltale sign of abdominal aortic aneurysm, usually motivating the request for paraclinical examination. It usually corresponds to the crack of the aneurysmal wall or the aneurysmal rupture. The frequency of acute abdominal pain varies according to the study: $52 \%$ in our series, $45 \%$ in the Rinckenbach study 17 and $22 \%$ in Carvalho's study ${ }^{13}$. For asymptomatic forms, the presence of a pulsatile abdominal mass is suggestive of AAA. The abdominal mass frequency observed in our series was identical in the De Carvalho study (47\%) 13 The presence of asymptomatic forms justifies routine screening of AAA in subjects over the age of 60 with several cardiovascular risk factors.

Two morphological examinations were requested in our series, ranging from a simple abdominal ultrasound to CT angiography of the abdominal aorta. In our series, abdominal ultrasound was used to diagnose eighteen patients (no.61). According to Liisberg, abdominal ultrasound offers moderate sensitivity ranging from $57.1 \%$ to $70.4 \%$ and high specificity ranging from $99.2 \%$ to $99.6 \%$ 18. In addition, the abdominal computed tomography can detect an aneurysm of the abdominal aorta. Forty-five of our patients $(74 \%)$ had performed an CT angiography of the abdominal aorta in our study. According to Claridge, the detection rate of an abdominal aortic aneurysm on routine abdominal computed tomography was 5.8\% 19. However, aortic doppler ultrasound (97\% in our series) and aortic CT angiography (74\% in our series) are the key examinations of pretherapeutic diagnosis and evaluation, measuring its diameter, morphology, the presence of intra-sacular thrombus, the association with the iliac or femoral artery and especially the measurement of the distance between the aneurysm collar from the distal edge of the renal artery 20 . The use of doppler ultrasound on the diagnostic in our series was (96.7\%) higher than in the De Carvalho study (3.9\%) ${ }^{13}$.

Evaluation of the diameter of the abdominal aorta is essential for the diagnosis and surgical treatment. The average diameter of the aneurysm sac measured in our series $(57.8 \mathrm{~cm})$ is similar to the study of Belarbi $(56 \mathrm{~cm}){ }^{15}$ and Muehling $(55 \mathrm{~cm}) 21$, significantly higher than the Carvalho study $(39 \mathrm{~cm}){ }^{13}$.

Literature says, the majority of aneurysms of the abdominal aorta is fusiform (80\%). Our study agrees with this literature data with $80.3 \%$ fusiform aneurysm and $19.7 \%$ sacciform form. De Carvalho's study showed $96.3 \%$ fusiform aneurysm and $3.7 \%$ sacciform aneurysm 13 .

The association of aortic aneurysm to the iliac or femoral artery is not exceptional. However, the rate of association with iliac or femoral arteries varied depending on the study our study showed $37.7 \%$ aorto-aortic aneurysm, 57.4\% aorto-bi-iliac aneurysm and $4.9 \%$ aorto-ilio-femoral aneurysm. The Carvalho study showed $13.2 \%$ association between aortic aneurysm to the iliac artery ${ }^{13}$. In addition, Rinckenbach's study showed 52\% aorto-aortic aneurysm, $28 \%$ aorto-bi-iliac aneurysm and 18\% aorto-bifemorale aneurysm ${ }^{17}$.

Without treatment, the natural evolution of subrenal abdominal aortic aneurysm is done towards the gradual size increase. However, the probability of rupture depends on several factors such as the size of the aneurysm $(5.5 \mathrm{~cm})$, the rate of expansion ( $1 \mathrm{~cm} /$ year), the morphology of the aneurysm and the genus 22 .

The management of subrenal abdominal aortic aneurysm is medical and surgical. In 2019, the recommendation of the European Society for Vascular Surgery (ESVS) calls for quitting smoking and taking medication, including statins associated with conversion enzyme inhibitors and platelet anti-aggregate 23, controlling other modifiable cardiovascular risk factors is important to slow the expansion of aneurysm. Surgical indication arises in front of a symptomatic aneurysm and an aneurysm with a diameter greater than $5.5 \mathrm{~cm} \mathrm{22,24}$, the goal of the treatment is to prevent aneurysmal rupture given the serious morbidity and mortality. In our study, therapeutic management was surgical in $63.93 \%$ and medical in $18.03 \%$. Conventional surgery by flattening graft remained our preferred technic, while in advanced countries endovascular surgery (EVAR) have an important role in the treatment of abdominal aortic aneurysm. The high cost of surgical consumables, especially prostheses, could explain the high rate (13\%) of discharge in our series. In our study, prosthetic replacement was $28.2 \%$ aorto-aortic, $66.7 \%$ aorto-bi-iliac and 5.1\% aorto-bifemoral. On the other hand, Rinckenbach's study of grafting flattening found $52 \%$ aorto-aortic prosthesis, $28 \%$ aorto-bi-iliac and $18 \%$ aorto-bifemoral ${ }^{17}$. 
According to the etiology, atheromatous origin is the most common (95\%) related to cardiovascular risk factors. Three to $10 \%$ of AAA are inflammatory. Takayashu's disease, Behçet's disease and, unusually, Horton's disease are mentioned. They represent a particular clinical entity whose diagnostic arguments are based primarily on clinical context, AAA imaging and the histological study of biopsy exhibits $27,28,29$

Postoperative evolution was favorable to $82 \%$ in our series and $58 \%$ in the Belarbi study 15 . The early postoperative mortality rate in our series was $5.1 \%$, this mortality rate was close to the other studies $4.9 \%$ the Fairman study $25,16 \%$ in the Belarbi study 15 .

\section{CONCLUSION}

Subrenal abdominal aortic aneurysm is a serious and fatal condition for complications, hence the need for routine screening for elder people with cardiovascular risk factors to avoid it. Medical treatment relies primarily on the control of cardiovascular risk factors, and surgery remains the only treatment for aneurysms with antero-posterior diameter greater than $50 \mathrm{~mm}$. Elsewhere, the endovascular technique is booming and yielding better results.

\section{REFERENCES}

1. Johnston KW, Rutherford RB, Tilson MD, Shah DM, Hollier L, Stanley JL. Suggested standards for reporting on arterial aneurysms. Subcommittee on reporting standards for arterialaneurysms, Societyfor Vascular Surgery and North American Chapter, InternationalSociety for Cardio-Vascular Surgery. J Vasc Surg 1991; 13:352-8.

2. Vilares A, da Silva MC, Negrao E, de Lima BF, Silva A. Evaluation of Abdominal Aortic Aneurysms: a pictorial review of common appearances and complications. European Congress of Radiology 2019. DOI:10.26044/ecr2019/C-3370

3. Li X, Zhao G, Zhang J, Duan Z, Xin S. Prevalence and trends of the abdominal aortic aneurysms epidemic in general population-a meta-analysis. PloS one 2013; 8(12):e81260.

4. Reite A, Søreide K, Ellingsen CL, Kvaløy JT, Vetrhus M. Epidemiology of ruptured abdominal aortic aneurysms in a well-defined Norwegian population with trends in incidence, intervention rate, and mortality. J Vasc Surg 2015; 61(5):116874.

5. Hallin A, Bergqvist D, Holmberg L. Literature review of surgical management of abdominal aortic aneurysm. Eur J Vasc Endovasc Surg 2001; 22:197-204.

6. Becker F, Baud JM. Dépistage des anévrysmes de l'aorte abdominale et surveillance des petits anévrysmes de l'aorte abdominale : argumentaire et recommandations de la Société française de médecine vasculaire. J Mal Vasc 2006; 31(5):26076.

7. Ouarab C, Brouri M, Laroche JP, Ayoub S. Prévalence et facteurs de risque de l'anévrysme de l'aorte abdominale sous-rénale dans une population algérienne âgée de plus de 60 ans. J Med Vascul 2018; 43:361-368.

8. Dieng PA, Diop MS, Ba PS, Diatta S, Gaye M, Sow NF, Diagne PA, Sene EB, Ciss AG, Ndiaye A, Ndiaye M. Chirurgie des anévrysmes de l'aorte abdominale sous rénale à Dakar. Ann Afr Chir Thor Cardiovasc 2007; 2(1):53-8

9. Gardet E, Pesteil F, e Guyader A, Preux PM, Laskar M. Résultat à court et à long terme de la chirurgie conventionnelle des Anévrysmes de l'aorte abdominale sous rénale. Chirurgie Thoracique Cardio-vasculaire 2010; 14:52-6

10. Stephane E, Gloviczki P, MDa.McKusick MA, Panneton JM, Andrews J, .Bower TC, Noel AA, Harmsen WS, .Hoskin TL, Cherry K. Endovascular Repair of Abdominal Aortic Aneurysms: Initial Experience With 100 Consecutive Patients. Mayo Clin Proc 2003; 78:1234-42.
11. Ting ACW, Cheng SWK, Ho p, Chan YC, Poon JTC, Yiu WK, Cheung GCY. Endovascular repair for abdominal aortic aneurysms: the first hundred cases. Hong Kong Med J 2008; 14:361-6.

12. Khan M, Davies C, Bhatti K, Strike P, Ghauri AS, Ranaboldo CJ. Reduced access aortic exposure (RAAE) technique for infrarenal abdominal aortic aneurysm (AAA) repair. International Journal of Surgery 2009; 7:159-62.

13. De Carvalho ATY, De Jesus SA, Gomes CAP, Martins ML, dos Santos VP, Rubeiz RP et al. Infrarenal abdominal aortic aneurysm: significance of screening in patients of public hospitals in the metropolitan region of Salvador-Bahia, Brazil. ] Vasc Bras 2012; 11(4):289-300.

14. Keisler B, Carter C. Abdominal aortic aneurysm. American family physician 2015; 91(8) :538-543.

15. Becker F, Baud JM. Dépistage des anévrysmes de l'aorte abdominale et surveillance des petits anévrysmes de l'aorte abdominale: Argumentaire et recommandations de la société française de médecine vasculaire. Elsevier Masson 2006; 31:260-76.

16. Upchurch GR Jr, Schaub TA. Abdominal aortic aneurysm. Am Fam Physician. 2006; 73(7):1198-1204.

17. Rinckenbach S, Albertini JN, Thaveau F, Steinmetz E, Camin A et al. Prise en charge préhospitalière des anévrysmes rompus de l'aorte abdominale sous rénale : analyse multicentrique. Ann vasc surg 2010; $24: 308-314$.

18. Liisberg M, Diederichsen AC, Lindholt JS. Abdominal ultrasoundscanning versus non-contrast computed tomography as screening method for abdominal aortic aneurysm-a validation study from the randomized DANCAVAS study. BMC medical imaging 2017; 17(1):14.

19. Claridge R, Arnold S, Morrison N, van Rij AM. Measuring abdominal aortic diameters in routine abdominal computed tomography scans and implications for abdominal aortic aneurysm screening. Journal of vascular surgery 2017; 65(6):1637-1642.

20. Reis SP, Majdalany BS, AbuRahma AF, Collins JD, Francois CJ, Ganguli $S$ et al. ACR appropriateness criteria ${ }^{\circledR}$ pulsatile abdominal mass suspected abdominal aortic aneurysm. Journal of the American College of Radiology 2017; 14(5):S258-S265.

21. Muehling BM, Meierhenrich R, Thiere M, Bischoff G, Oberhuber $\mathrm{A}$, Orend $\mathrm{KH}$, \& Sunder-Plassmann. The retroperitoneal approach combined with epidural anesthesia reduces morbidity in elective infrarenal aortic aneurysm repair. Interactive cardiovascular and thoracic surgery 2009; 8(1):35-39.

22. Wang LJ, Prabhakar AM, Kwolek CJ. Current status of the treatment of infrarenal abdominal aortic aneurysms. Cardiovascular diagnosis and therapy 2018; 8(Suppl 1): S191.

23. Wanhainen A, Verzini F, Van Herzeele I, Allaire E, Bown M, Cohnert $\mathrm{T}$ et al. Editor's choice-European society for vascular surgery (ESVS) 2019 clinical practice guidelines on the management of abdominal aorto-iliac artery aneurysms. European Journal of Vascular and Endovascular Surgery 2019; 57(1):8-93.

24. Chaikof EL, Dalman RL, Eskandari MK, Jackson BM, Lee WA, Mansour MA et al. The Society for Vascular Surgery practice guidelines on the care of patients with an abdominal aortic aneurysm. Journal of vascular surgery 2018; 67(1):2-77.

25. Fairman AS, Chin AL, Jackson BM, Foley PJ, Damrauer SM, Kalapatapu $\mathrm{V}$ et al. The evolution of open abdominal aortic aneurysm repair at a tertiary care center. Journal of Vascular Surgery 2020. DOI: 10.1016/j.jvs.2019.12.039

26. Solofomalala GD, Rakotomalala JY, Rakotoarisoa AJC, Razafindramboa H, Ranaivozanany A. La chirurgie de l'anévrisme de l'aorte abdominale à Madagascar. Médecine d'Afrique noire 2006; 53:11-4.

27. Huart J.Y, Chocron S. Anévrysme de l'aorte abdominale sous rénale. 2008. http://www.besancon- cardio.org.

28. Magne J L, Sessa C, Penillon S. Anévrysme de l'aorte abdominale. Polycopiés 131B. Faculté de Médecine de Grenoble. Mai 2005. http://medecinevasculaire. angioweb.org/enseignant/poly/131BAnévrysmes.pdf

29. Tang T, Boyle J.R., Dixon A.K, Varty K. Inflammatory abdominal aortic aneurysms. Eur J Vasc Endovasc Surg 2005; 29:353- 362 